\title{
BMJ Open Assessment of surgical capacity in Chiapas, Mexico: a cross-sectional study of the public and private sector
}

\author{
Lina Roa (D) , ${ }^{1,2}$ Ellie Moeller (1D , ${ }^{1,3}$ Zachary Fowler, ${ }^{1}$ Fernando Carrillo, ${ }^{4}$ \\ Sebastian Mohar, ${ }^{4,5}$ Wendy Williams, ${ }^{6}$ John G Meara, ${ }^{7}$ Robert Riviello, ${ }^{1,6}$ \\ Tarsicio Uribe-Leitz, ${ }^{1,6}$ Valeria Macias ${ }^{4}$
}

To cite: Roa L, Moeller E, Fowler Z, et al. Assessment of surgical capacity in Chiapas, Mexico: a cross-sectional study of the public and private sector. BMJ Open 2021;11:e044160. doi:10.1136/ bmjopen-2020-044160

- Prepublication history and supplemental material for this paper is available online. To view these files, please visit the journal online (http://dx.doi. org/10.1136/bmjopen-2020044160).

LR and EM are joint first authors. TU-L and VM are joint senior authors.

Received 25 August 2020 Accepted 08 June 2021
Check for updates

(C) Author(s) (or their employer(s)) 2021. Re-use permitted under CC BY-NC. No commercial re-use. See rights and permissions. Published by BMJ.

For numbered affiliations see end of article.

Correspondence to

Dr Ellie Moeller;

ellie.moeller@med.miami.edu

\section{ABSTRACT}

Introduction Surgical, anaesthesia and obstetric (SAO) care are essential, life-saving components of universal healthcare. In Chiapas, Mexico's southernmost state, the capacity of SAO care is unknown. This study aims to assess the surgical capacity in Chiapas, Mexico, as it relates to access, infrastructure, service delivery, surgical volume, quality, workforce and financial risk protection. Methods A cross-sectional study of Ministry of Health public hospitals and private hospitals in Chiapas was performed. The translated Surgical Assessment Tool (SAT) was implemented in sampled hospitals. Surgical volume was collected retrospectively from hospital logbooks. Fisher's exact test and Mann-Whitney U test were used to compare public and private hospitals. Catastrophic expenditure from surgical care was calculated.

Results Data were collected from 17 public hospitals and 20 private hospitals in Chiapas. Private hospitals were smaller than public hospitals and public hospitals performed more surgeries per operating room. Not all hospitals reported consistent electricity, running water or oxygen, but private hospitals were more likely to have these basic infrastructure components compared with public hospitals ( $84 \%$ vs $95 \% ; 60 \%$ vs $100 \% ; 94.1 \%$ vs $100 \%$, respectively). Bellwether surgical procedures performed in private hospitals cost significantly more, and posed a higher risk of catastrophic expenditure, than those performed in public hospitals.

Conclusion Capacity limitations are greater in public hospitals compared with private hospitals. However, the cost of care in the private sector is significantly higher than the public sector and may result in catastrophic expenditures. Targeted interventions to improve the infrastructure, workforce availability and data collection are needed.

\section{INTRODUCTION}

Surgical, anaesthesia and obstetric (SAO) care are essential, life-saving components of universal healthcare. In spite of this, SAO care often does not meet the burden of disease, especially in resource-limited regions. ${ }^{1}$ It is estimated that 143 million additional surgical procedures are needed annually to address the surgical burden of disease, and the majority of these procedures are needed in

\section{Strengths and limitations of this study}

- This is one of the first studies to comprehensiveIy measure the surgical capacity in a Central American region within the framework of the Lancet Commission on Global Surgery indicators and in accordance with capacity assessments of surgical care in other countries.

- Our measurement of surgical capacity in the state enables specific strengths and challenges to be identified to support informed policy decisions to improve care for the state's population.

- Public hospitals are government-funded and are required to report health metrics to the Mexican Ministry of Health, while private hospitals do not have the same requirements and therefore these health metrics are often not well understood. This study analysed health metrics in both public and private hospitals.

- Public hospitals could not be randomly sampled due to travel and safety concerns. Instead they were sampled by stratified convenience sampling to include a basic and general hospital, when existent, from each of the 10 health districts.

- Collecting data with the Surgical Assessment Tool may result in potential biases, including ascertainment, recall, observer and interviewer bias.

low-income and middle-income countries. ${ }^{2}$ Even within countries, accessibility and quality of SAO care can vary dramatically, often stemming from health system factors including inequity, poverty and structural violence. ${ }^{3-6}$

Mexico is an upper-middle-income country with dramatic income inequality, having extremes of both wealth and poverty. ${ }^{7-9}$ The state of Chiapas, situated on Mexico's southernmost border, is on one extreme, with more than $75 \%$ of the state's population living below the nation's rural and urban poverty lines (figure 1). ${ }^{10}$ Health service delivery can be limited in Chiapas, especially in geographically isolated areas where more 


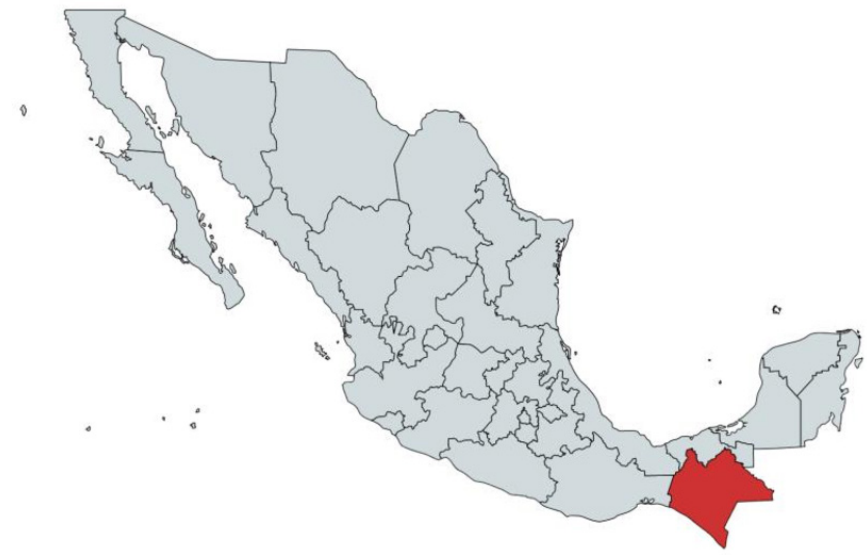

Figure 1 The state of Chiapas, Mexico, shown in red.

than three-quarters of the population resides. ${ }^{11-13}$ In Chiapas and throughout Mexico, SAO care is provided by both public and private hospitals. ${ }^{14}{ }^{15}$ Public hospitals are government-funded and are required to report health metrics to the Mexican Ministry of Health, while private hospitals do not have the same requirements. ${ }^{16}$ Although some data are collected on SAO care in public hospitals, the overall private surgical capacity of the state of Chiapas is unknown.

There are several systemic and structural components of SAO capacity that play a role in ensuring care that is comprehensive, safe, timely and affordable. To quantify this, the Lancet Commission on Global Surgery (LCoGS) recommended all countries collect indicators that contribute to SAO capacity (table 1 ). ${ }^{2}$ This study aimed to measure the surgical capacity in Chiapas within the framework of the LCoGS indicators measurable in Chiapas and in accordance with capacity assessments of surgical care in other countries. ${ }^{2}{ }^{3}$ Little is known about the access, infrastructure, surgical volume, perioperative mortality rate, workforce and financial risk protection as it relates to surgical care in Chiapas. By measuring these domains of SAO care, specific strengths and challenges can be identified to support informed policy decisions to improve care for the state's population. The purpose of this study is to measure and analyse the surgical capacity of public and private hospitals in Chiapas, Mexico. This manuscript is the quantitative component of a mixedmethods study, with the qualitative piece published at a later date.

\section{METHODS}

\section{Setting}

Mexico provides health insurance through a national social security system. Formal workers and their families receive health insurance through multiple national social security institutions such as the Mexican Social Security Institute (IMSS) for industry workers, ISSSTE for federal government employees, SEDENA for armed forces, SEMAR for the navy and PEMEX for oil industry employees. ${ }^{17} 18$ In Chiapas, the insurance scheme
ISSTECH provides insurance for state government employees. ${ }^{19}$ Each insurance scheme corresponds to designated hospitals specific to the patients covered by that insurance type.

For citizens outside the formal workforce, the public insurance scheme Seguro Popular provided insurance coverage for millions of low-income Mexicans until it was replaced by INSABI (Instituto de Salud para el Bienestar) in January 2020. ${ }^{20}{ }^{21}$ Hospitals providing care through Seguro Popular were public hospitals provided and operated by the Ministry of Health. In the state of Chiapas, Mexico, more than $69 \%$ of the state's 5.3 million residents were enrolled in the government-funded Seguro Popular while less than $1 \%$ had private insurance. ${ }^{22} 23$ Despite a scheme for universal health coverage through public insurance, the health system remains fragmented with care delivered through several parallel insurance and hospital systems.

The Ministry of Health stratifies public hospitals by care level (community, general and federal) and by 10 health districts in the state of Chiapas. In regard to surgical care, community hospitals are defined as those providing general surgery. General hospitals are defined as providing general surgery, as well as gynaecological and orthopaedic surgery. ${ }^{20}$ Federal hospitals are defined as providing all surgical specialties available at lower level hospitals in addition to surgical subspecialties. ${ }^{20}$ Private hospitals do not have defined levels of care or services provided.

\section{Study design}

We conducted a stratified cross-sectional study of surgical capacity using a mixed-methods approach in the state of Chiapas, Mexico, from September to December 2019 in accordance with the Strengthening the Reporting of Observational Studies in Epidemiology guidelines. ${ }^{24}$ Here we present the quantitative results. The qualitative manuscript will be presented elsewhere.

\section{Subjects}

Inclusion criteria were all Ministry of Health public hospitals and private hospitals in Chiapas that perform at least one of the three bellwether procedures (laparotomy, management of open fracture and caesarean section), which are a proxy for a hospital's ability to provide essential surgical care. ${ }^{25} 26$ Since community hospitals are designated to provide general surgery, and therefore a laparotomy, our inclusion criteria was to perform at least one bellwether procedure. We did not anticipate all hospitals to perform all three bellwether procedures based on their government designation. Performance of the bellwether procedures in public hospitals was determined using the national open-access database, Cubos Dinámicos, which contains aggregate healthcare data from public hospitals. ${ }^{16}$ At the time of sampling, patients receiving care from public hospitals included those with the public insurance scheme Seguro Popular. Since there is no database for private hospitals, all private hospitals in 


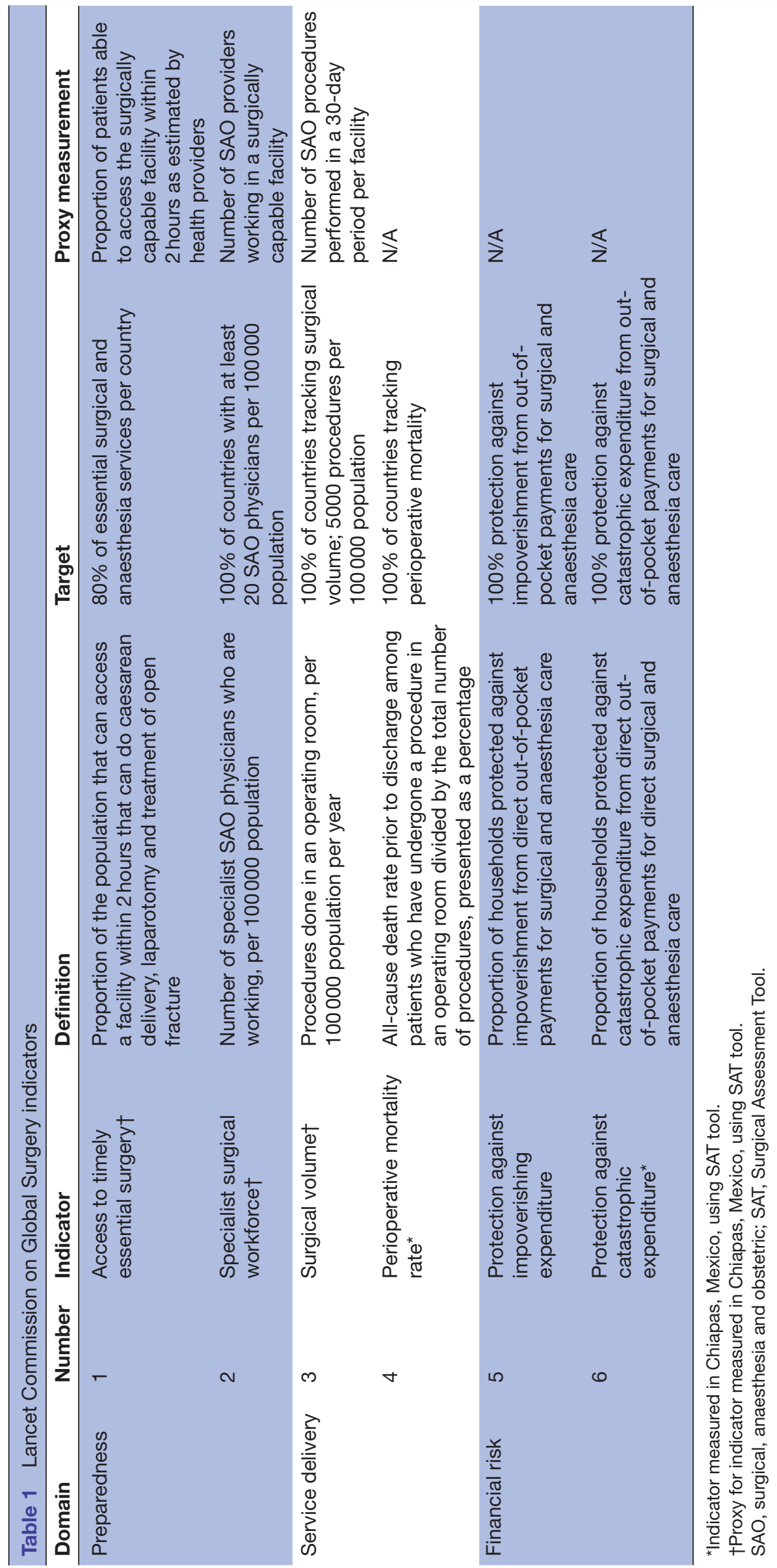


the state were contacted in person or by phone and asked if they perform at least one of the three bellwether procedures, to keep the consistency with the inclusion criteria for the public sector.

Public hospitals were sampled by stratified convenience sampling to include a basic and general hospital, when existent, from each of the 10 health districts. Due to safety concerns regarding travel in certain areas of the state, the hospitals within these strata were not chosen at random. One federal hospital in the state capital, Tuxtla Gutiérrez, was sampled. In districts in which the women's hospital was separated from the general hospital, the women's hospital was visited as well to capture obstetric and gynaecological care and was classified as a general hospital. All private hospitals in Chiapas were contacted in person or by phone, informed of the study and invited to participate.

\section{Tool}

The Surgical Assessment Tool (SAT) was adapted and implemented through in-person data collection in the sample hospitals in Chiapas. ${ }^{27}$ The SAT is a validated tool developed through collaboration between the WHO and the Program in Global Surgery and Social Change at Harvard Medical School. Translation of the SAT was conducted by a bilingual researcher, checked for accuracy by two clinicians (SM and VM) and researchers (LR and TU-L), and piloted in one hospital. After the pilot, minor modifications to the language but not to the content were made.

The SAT measures outcomes in the seven SAO capacity domains (online supplemental appendix A). Surgical volume data were collected from hospital logbooks. The remaining domains were completed in collaboration with hospital administrators, surgeons, obstetricians, anaesthesiologists, surgical nurses, accountants and social workers. The SAT was administered in Spanish and in-person at each hospital by three researchers (FC, ZF and EM). All SATs completed by sampled hospitals were included in the analysis.

\section{Definitions}

Surgical capacity categories were aligned with previously used frameworks for surgical capacity ${ }^{3}$ and with the the LCoGS indicator definitions (LCoGS Indicators \#4 and \#6), or by a proxy measurement for the LCoGS indicators (LCoGS Indicators \#1, \#2 and \#3; table 1).

Access to care was defined as the proportion of patients able to arrive at the surgically capable facility in 2 hours or less (proxy measurement for LCoGS Indicator \#1; table 1) ${ }^{28}$ Infrastructure included hospital capacity (number of hospital beds, operating rooms (ORs), postoperative recovery beds and ventilators), basic utilities (electricity, running water, internet, oxygen), airway management, OR equipment and consumable resources. Airway management equipment refers to resources that may be needed to safely secure or monitor an airway, and includes oropharyngeal airways, endotracheal tubes, laryngoscopes and bag valve masks for both adult and paediatric patients. OR equipment refers to a suction device, a light source, an equipment steriliser (autoclave or disinfectant), electrocautery, forceps, scissors and needle drivers. Consumable resources include both consumable equipment and blood products. Consumable equipment refers to essential surgical items including sterile gloves, examination gloves, chest tubes, urinary catheters, nasogastric tubes and sutures. All infrastructure items that were included were functional at the time of assessment. Service delivery included surgical volume and perioperative mortality rate (POMR). Surgical volume was measured using SAO logbook recordings of procedures that occurred in the 30-day sample period (proxy measurement for LCoGS Indicator \#3). POMR was calculated by the number of deaths divided by the total operative procedures performed in the 30-day sample period (LCoGS Indicator \#4). Workforce was defined as the SAO providers working in a surgically capable facility (proxy measurement for LCoGS Indicator \#2). Financial risk protection included risk of catastrophic expenditure, which was defined as direct medical and non-medical outof-pocket expenditure greater than $10 \%$ of annual income (LCoGS Indicator \#6).

\section{Statistical analysis}

Public hospitals were stratified by the care level (community, general, federal) designated by the Ministry of Health. Private hospitals were stratified by the number of OR, a proxy for surgical care level. Private hospitals were therefore categorised as having one OR, two ORs or three ORs.

Descriptive statistics were performed. Fisher's exact tests were used for categorical variables comparing public and private hospitals in Chiapas. Mann-Whitney $\mathrm{U}$ test was used for continuous variables comparing public and private hospitals. Facilities were removed from particular analyses when variables of interest were missing but remained in the data set for analysis of all other available data. Catastrophic expenditure was defined as direct medical and non-medical out-of-pocket expenditure greater than $10 \%$ of annual income. ${ }^{28}$ Out-of-pocket expenditure, mean income per capita and Gini coefficient were obtained from the SAT and Instituto Nacional de Estadística y Geografia and were used to generate a stochastic model based on a $\gamma$ distribution of income for Chiapas. ${ }^{29}$ Mean percentage experiencing catastrophic expenditure was estimated, based on cohorts of 1 million individuals that were constructed for 500 parameter draws and reported with $95 \%$ uncertainty intervals (UI). Prices were converted to US dollars and adjusted by purchasing power parity for private consumption (World Bank 2018) ${ }^{28}$ Data management was done in Microsoft Excel V.16.30. Statistical analysis was performed using SAS V.9.4.

\section{RESULTS}

We identified a total of 90 hospitals capable of providing at least one bellwether surgical procedure in the state 


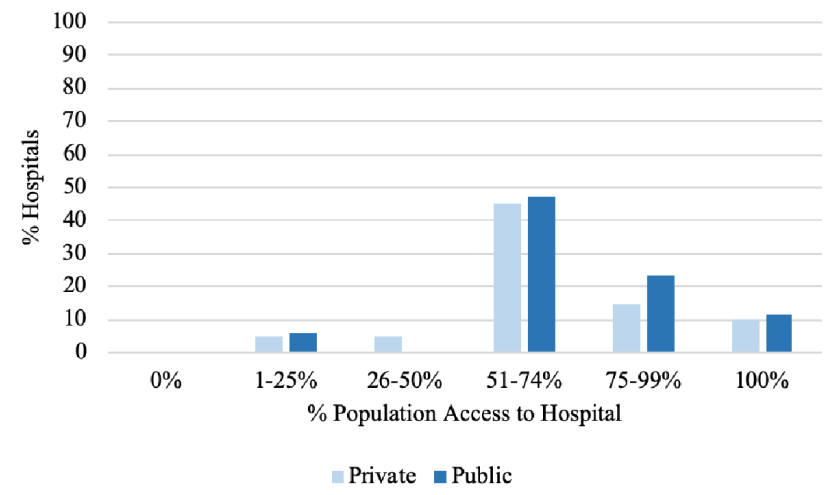

Figure 2 Hospitals reporting proportion of patients that can reach care within 2-hour access.

of Chiapas, 32 public (2 federal, 15 general, 15 basic community) and 58 private hospitals. Data were collected in-person during a hospital visit from 37 hospitals in Chiapas, of which 17 were public (1 federal, 9 general, 7 basic community) and 20 were private. The 20 private hospitals were those which consented to participating in the study. This sample represented $53.1 \%$ of public hospitals and $34.5 \%$ of private hospitals in the state.

\section{Access}

Four facilities (10.8\%), two public (11.8\%) and two private $(10 \%)$, reported that patients were always able to arrive at their facility in less than 2 hours (figure 2). Most public hospitals $(n=8,47.1 \%)$ and private hospitals $(n=9$, $45 \%$ ) reported half to three-quarters of patients were able to arrive at the facility within 2 hours.

Of the 37 hospitals surveyed, 13 hospitals (35\%) performed the three bellwether procedures (caesarean section, laparotomy and open fracture repair). Three public hospitals $(17.6 \%)$ and 10 private hospitals $(50 \%)$ reported the ability to perform all bellwether procedures $(\mathrm{p}=0.08)$.

\section{Infrastructure}

Overall, private hospitals were smaller than public hospitals, with fewer hospital beds, postoperative recovery beds and ventilators per OR (table 2). Across all sampled hospitals, the median bed capacity was 12 beds (IQR 23). The median bed capacity in all public hospitals was greater than in all private hospitals (30 (IQR 40) vs 7.5 (IQR

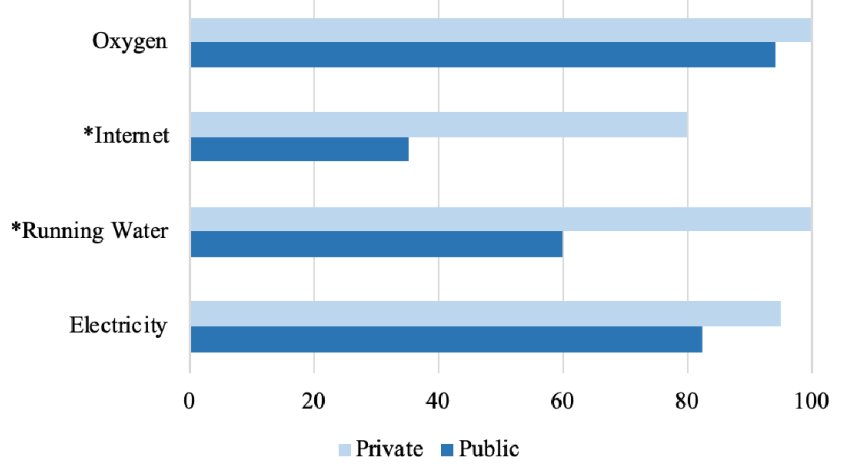

Figure 3 Percentage of hospitals that always had available basic infrastructure in Chiapas, Mexico. *Denotes statistical significance of $\mathrm{p}<0.05$.

9.5)). Additionally, public facilities had a higher median of ORs compared with private facilities (2 (IQR 2) vs 1.5 (IQR 1)). Six public hospitals $(35.3 \%)$-five general and the one federal hospital-and six private hospitals $(30 \%)$ had an intensive care unit (ICU). The median number of ventilators in hospitals with an ICU was 7.25 (IQR 9.25) in public hospitals and 2 (IQR 1) in private hospitals.

Not all public or private hospitals always had functional electricity, running water, internet and oxygen (figure 3). Electricity was always functional in $82.4 \% \quad(n=14)$ of public hospitals and in $95 \%(n=19)$ of private hospitals $(\mathrm{p}=0.32)$. Running water was always available in significantly more private hospitals than public hospitals $(100 \%$ private vs $60 \%$ public, $\mathrm{p}=0.014)$. Internet was always available in less than half of public facilities $(35.3 \%, \mathrm{n}=6)$ and was always available in more private facilities $(80 \%, \mathrm{n}=16)$ $(\mathrm{p}=0.008)$. Of the five public hospitals where internet was never available $(29.4 \%)$, three were basic hospitals and two were general hospitals. Oxygen was always available in $94.1 \%$ of public facilities $(n=16)$ and $100 \%$ of private facilities $(n=20 ; p=0.46)$.

\section{Infrastructure: airway management equipment}

Overall $94.1 \%(\mathrm{n}=16)$ of public hospitals and $95 \%$ $(n=19)$ of private hospitals reported availability of airway management equipment. All of the 19 responding private hospitals reported always having airway management equipment available, whereas this equipment was not always available in the responding public hospitals

Table 2 Infrastructure capacity by hospital type and level presented as median (IQR)

\begin{tabular}{|c|c|c|c|c|c|c|}
\hline \multirow[b]{2}{*}{ Components of infrastructure capacity } & \multicolumn{3}{|c|}{ Public hospitals by level } & \multicolumn{3}{|c|}{ Private hospitals by ORs } \\
\hline & Basic & General & Federal & One OR & Two ORs & Three ORs \\
\hline Hospital beds & $12(8)$ & $60(30)$ & 90 & $4.5(2.5)$ & $12(3)$ & $19.5(13.3)$ \\
\hline Postoperative recovery beds & $2(1)$ & $5(2.75)$ & 6 & $1(1)$ & $1(0)$ & $1.5(3.3)$ \\
\hline Ventilators & $0(0)$ & $7.3(9.3)$ & 11 & $0(1)$ & $0(0)$ & $4(3)$ \\
\hline
\end{tabular}

ORs, operating rooms. 


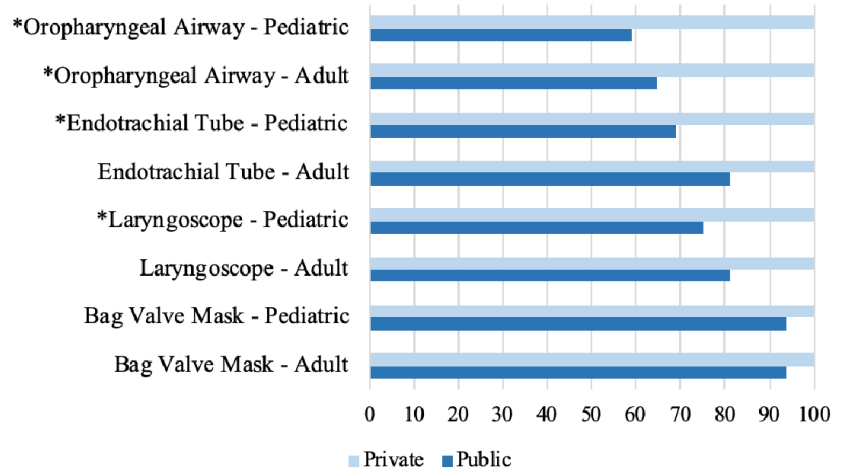

Figure 4 Percentage of hospitals that are always available with airway management equipment $\dagger$ available in Chiapas, Mexico. *Denotes statistical significance of $p<0.05$. †Airway management equipment refers to resources that may be needed to safely secure or monitor an airway, and includes oropharyngeal airways, endotracheal tubes, laryngoscopes and bag valve masks for both adult and paediatric patients.

(figure 4). Significantly more private hospitals always had available adult and paediatric oropharyngeal airways ( $\mathrm{p}=0.014$ and $\mathrm{p}=0.005$, respectively), paediatric endotracheal tubes $(p=0.014)$ and paediatric laryngoscopes $(\mathrm{p}=0.034)$ compared with public hospitals.

\section{Infrastructure: OR equipment}

OR equipment availability was reported by $94.1 \%$ of public hospitals $(\mathrm{n}=16)$ and $95 \%$ of private hospitals $(n=19)$. More private hospitals than public hospitals had OR equipment always available (figure 5), including suction $(100 \%$ vs $86.7 \%$; $\mathrm{p}=0.19)$, a light source $(89.5 \%$ vs $75 \%$; $\mathrm{p}=0.22)$, a steriliser $(89.5 \%$ vs $56.3 \%$; $\mathrm{p}=0.05)$, electrocautery $(94.7 \%$ vs $68.8 \%$; $\mathrm{p}=0.04)$, forceps $(42.1 \%$ vs $31.3 \%$; $\mathrm{p}=0.73)$, scissors $(100 \%$ vs $87.5 \%$; $\mathrm{p}=0.2)$ and needle driver $(100 \%$ vs $87.5 \%$; $=0.2)$.

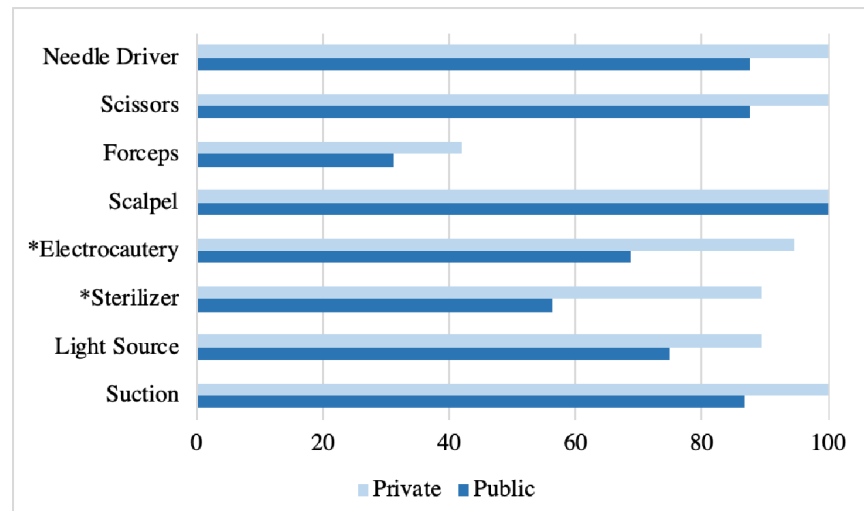

Figure 5 Percentage of hospitals with operating room equipment $\dagger$ always available in Chiapas, Mexico. ${ }^{*}$ Denotes statistical significance of $p<0.05$. †Operating room equipment refers to a suction device, a light source, an equipment steriliser (autoclave or disinfectant), electrocautery, forceps, scissors and needle drivers.

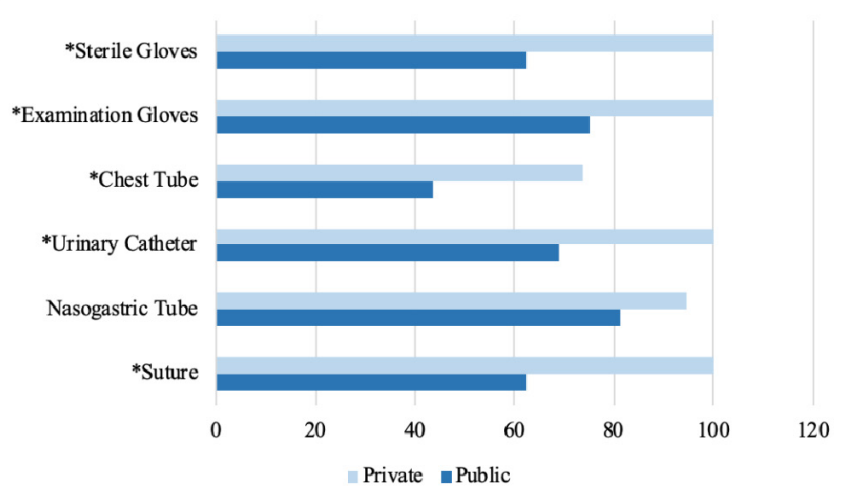

Figure 6 Always available consumablest in public and private hospitals in Chiapas, Mexico. ${ }^{*}$ Denotes statistical significance of $p<0.05$. †Consumable resources include both consumable equipment and blood products. Consumable equipment refers to essential surgical items including sterile gloves, examination gloves, chest tubes, urinary catheters, nasogastric tubes and sutures.

\section{Infrastructure: consumables}

Overall, $94.1 \%$ of public hospitals $(n=16)$ and $95 \%$ of private hospitals $(n=19)$ reported availability of consumable equipment (figure 6). All responding private hospitals $(100 \%)$ reported having sterile gloves, examination gloves, urinary catheters and sutures always available. Comparatively, not all public hospitals always had these resources, with $62.5 \% \quad(n=)$ always having sterile gloves $(p=0.005), 75 \%$ always having examination gloves $(p=0.035), 68.8 \%$ always having urinary catheters $(\mathrm{p}=0.014)$ and $62.5 \%$ always having sutures $(\mathrm{p}=0.005)$. Chest tubes were always available in $43.8 \%$ of public hospitals and $73.7 \%$ of private hospitals $(\mathrm{p}=0.09)$. Nasogastric tubes were always available in $81.3 \%$ of public hospitals and $94.7 \%$ of private hospitals $(\mathrm{p}=0.31$ ).

More private hospitals (65\%) were able to perform a blood transfusion in less than 2 hours compared with public hospitals (53\%), although this difference was not significant $(\mathrm{p}=0.5)$.

\section{Service delivery}

Following the LCoGS framework we assessed two main components of service delivery: surgical volume and POMR.

\section{Surgical volume}

Among all sampled hospitals, the median number of operations per OR per month was 24 (IQR 30). The public sector performed more surgeries per OR as compared with the private sector (median 38 (IQR 48.7) versus median 18.5 (IQR 28.9), respectively). In both public and private hospitals, the increase in ORs was associated with greater productivity, as measured by median operations per OR per month (table 3). However, the public sector performed significantly more surgeries per OR as compared with the private sector $(\mathrm{U}=89.5, \mathrm{p}<0.05)$. 


\begin{tabular}{|c|c|c|c|c|c|c|}
\hline & \multicolumn{3}{|c|}{$\begin{array}{l}\text { Public hospitals by level } \\
(n=17)\end{array}$} & \multicolumn{3}{|c|}{$\begin{array}{l}\text { Private hospitals by ORs } \\
(n=20)\end{array}$} \\
\hline & $\begin{array}{l}\text { Basic } \\
(n=7)\end{array}$ & $\begin{array}{l}\text { General } \\
(n=9)\end{array}$ & $\begin{array}{l}\text { Federal } \\
(n=1)\end{array}$ & $\begin{array}{l}\text { One OR } \\
(n=10)\end{array}$ & $\begin{array}{l}\text { Two ORs } \\
(n=6)\end{array}$ & $\begin{array}{l}\text { Three ORs } \\
(n=4)\end{array}$ \\
\hline Median (IQR) number of operations per OR in 1 month & $12.9(39)$ & $40(76.7)$ & 36.5 & $12(14)$ & $44(63.3)$ & $79(42.5)$ \\
\hline
\end{tabular}

OR, operating room.

\section{Perioperative mortality rate}

POMR in public hospitals was $0.73 \%(14 / 1921)$ and $0.12 \%(1 / 815)$ in the private sector during the 30 -day sample period.

\section{Workforce}

There was a total of $671 \mathrm{SAO}$ providers among all sampled hospitals, with 355 working full-time in public hospitals and 316 working full-time in private hospitals. Of the fulltime SAO providers in public hospitals, $174(49 \%)$ also worked part-time in the private sector. Of the 316 fulltime SAO providers in the private sector, $226(71.5 \%)$ worked part-time in the public sector as well.

Among all sampled hospitals, 171 (25.5\%) SAO providers were women. There were 92 (25.9\%) full-time female SAO providers in public hospitals and 79 (25\%) full-time female SAO providers in private hospitals.

Availability of SAO providers varied among public and private hospitals and by hospital level (figure 7). A surgeon, anaesthesiologist and obstetrician were all available $24 / 7$ in $11.8 \%(n=2)$ of public hospitals and $55 \%$ of private hospitals $(\mathrm{n}=11)$. In none of the basic public hospitals were general surgeons available $24 / 7$. Surgeons were available $24 / 7$ in $44.4 \%(n=4)$ of general public hospitals, always in the federal public hospital and in $60 \%(n=12)$ of private hospitals. Obstetricians were never available 24/7 in the basic public hospitals. They were available 24/7 in $55.6 \%(\mathrm{n}=5)$ of general public hospitals and in $70 \%$ $(\mathrm{n}=14)$ of private hospitals. Anaesthesiologists were available $24 / 7$ in $14.3 \%(\mathrm{n}=1)$ basic public hospitals, $77.8 \%$

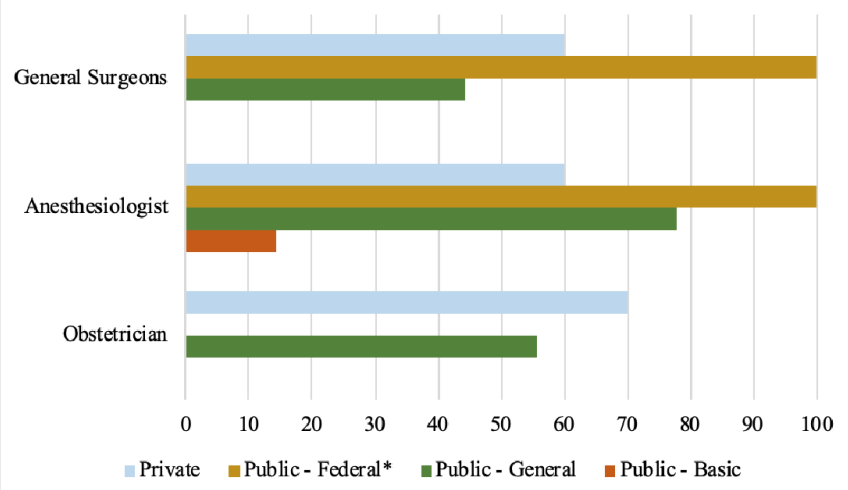

Figure 7 Percentage of hospitals with surgical, anaesthesia and obstetric providers always available. ${ }^{*}$ Public - Federal: Federal hospital without obstetrics and gynaecology. $(n=7)$ of general public hospitals, always in the federal public hospital and in $60 \%(n=12)$ of private hospitals.

\section{Insurance and financial risk protection}

Seguro Popular was the most commonly held health insurance of patients seeking care in public hospitals, with $84.5 \%$ of these patients on average being covered. Conversely, $50 \%$ of patients seeking care in private hospitals had Seguro Popular.

Patients covered by the government insurance scheme Seguro Popular did not pay for their treatment in public hospitals. However, if a public hospital did not have certain equipment or medications available, the patient may have incurred an out-of-pocket medical cost by needing to purchase the item herself (table 4). Patients seeking care in public hospitals who were not covered by Seguro Popular paid a fixed amount determined by an income-based sliding scale. Patients seeking care in private hospitals who did not have private insurance paid an amount determined by the private facility. Out-ofpocket non-medical costs included transportation, food and housing and were higher for patients seeking care in public hospitals compared with private hospitals.

Based on the out-of-pocket expenditure in table 4, the estimated percentage of patients covered by Seguro Popular at risk of catastrophic expenditure at public hospitals was $5.2 \%$ (95\% UI: $4.4 \%-6.1 \%)$. The population estimated to be at risk of catastrophic expenditure based on the median cost (medical and non-medical) in the private sector for a caesarean section was $80.6 \%(95 \%$ UI: $79.5 \%-81.6 \%$ ). For a laparotomy in the private sector, $85.9 \%$ (95\% UI: $85 \%-86.7 \%$ ) of the population was at risk of catastrophic expenditure. The population at risk of catastrophic expenditure based on the median cost in the private sector for repair of an open fracture was 93.2\% (95\% UI: $92.7 \%-93.7 \%$ ).

\section{DISCUSSION}

This study assessed the surgical capacity in the state of Chiapas, Mexico, through analysis of seven domains of health systems. While some metrics of SAO care are reported to the Ministry of Health by public hospitals, the overall surgical capacity of the state of Chiapas has not been characterised. This study identified strengths and gaps of the surgical system and found that there 
Table 4 Expenses incurred by patients in public and private hospitals

Cost in Mexican pesos

Cost in US dollars adjusted by purchasing power parity ${ }^{28}$

\begin{tabular}{lll}
\cline { 2 - 3 } Expense & Public hospital without insurance, ${ }^{*}$ range & Private hospital, median (IQR) \\
\hline Caesarean section & $0-1559$ & $16750(10750)$ \\
Laparotomy & $0-151.01$ & $1623.06(1041.67)$ \\
Open fracture repair & $0-1181$ & $20000(18750)$ \\
& $0-114.44$ & $1937.98(1816.86)$ \\
Out-of-pocket medical cost)† & $0-1750$ & $27500(33125)$ \\
& $0-169.57$ & $2664.73(3209.79)$ \\
Out-of-pocket non-medical costł & Public hospital without insurance, median (IQR) & Private hospital, median (IQR) \\
& $1075(875)$ & $2000(3350)$ \\
& $104.17(84.79)$ & $193.80(324.61)$ \\
& $400(1150)$ & $500(752.3)$ \\
\end{tabular}

*Patients seeking care in public hospitals who were not covered by Seguro Popular paid a fixed amount determined by an income-based sliding scale.

†Includes purchased medications, equipment or other surgical, anaesthesia and obstetric products.

łIncludes housing, transportation and food during hospitalisation.

are significant differences in essential surgical capacity between public and private hospitals.

Essential surgical capacity varied between public and private hospitals in the areas of service capacity, infrastructure and operative volume. Not all public or private hospitals always had functional electricity, running water or oxygen, but private hospitals were more likely to have these basic infrastructure components compared with public hospitals ( $84 \%$ vs $95 \%$; $60 \%$ vs $100 \%$; $94.1 \%$ vs $100 \%$, respectively). Furthermore, significantly more private hospitals had running water and internet compared with public hospitals. Unavailable basic amenities like running water can prevent even basic surgical or obstetric interventions, or dramatically reduce a procedure's safety. ${ }^{30}$

In spite of more infrastructure shortages, public hospitals were larger than private hospitals on average, and had more hospital beds, postoperative recovery beds and ventilators per OR. Public hospitals were also more productive on average than private hospitals, demonstrated by performing more surgical procedures per OR in 1 month (median 38 vs median 18.5). Productivity as reflected by percentage of daily OR usage has been identified as an indicator of high-quality surgical care. ${ }^{31} 32$ Despite high productivity in the public sector, large surgical volume in a state where $80 \%$ of the population is covered by government insurance could overwhelm hospital capacity which has been shown to increase care delays in Mexican public hospitals. ${ }^{30}$ The high demand for treatment and resulting care delays may result in more complicated patients being treated in public hospitals compared with private, contributing to higher POMR observed in the public sector $(0.73 \%$ vs $0.12 \%$, respectively). Similar trends have been described in trauma mortality outcomes in Latin America. ${ }^{33}$ Compared with other countries in Latin America, the POMR in public hospitals is comparable to that of Colombia $(0.73 \%)$ while both public and private hospitals have a lower POMR than that of Brazil $(1.6 \%) \cdot{ }^{34}{ }^{35}$ However, mortality rates in public hospitals may also be impacted by patients delaying treatment due to lack of hospital capacity, financial limitations or difficulty taking time off work. ${ }^{30}$ Another important patient population to consider are indigenous residents of Chiapas, who compose about $36 \%$ of the state's population but represent $50 \%$ of maternal mortality deaths in the state. ${ }^{22} 35$ This population faces unique barriers that may impact SAO care, including language barriers, cultural differences and mistreatment by the medical system, both of which can result in delays in seeking care and poor outcomes. ${ }^{22} 35$

The availability of SAO providers varied by provider type and among hospital levels and sectors. Only 35\% of all hospitals reported always having a surgeon, obstetrician and anaesthesiologist available. The lack of available SAO providers can contribute to the third delay in care in which a patient seeks care and reaches a facility but does not receive timely treatment. ${ }^{36}$ This may be further exacerbated by mismatches in providers, such as a surgeon being available without an anaesthesiologist. Unavailable SAO providers not only limit emergency care but also can result in disease progression and increased patient cost. Additionally, provider mismatches in already resource-poor settings can lead to inefficiencies in valuable resources. This is exemplified by an anaesthesiologist being available 24/7 without an available surgeon or obstetrician, as was the case in one quarter of public hospitals.

SAO care delivered by private hospitals resulted in significantly higher costs to patients. While some patients may seek care initially in the private sector, it is possible that other patients intend to receive treatment in the public sector but are unable to. Lack of infrastructure, 
equipment and unavailable providers in the public sector may necessitate obtaining SAO care at a private hospital, exacerbating out-of-pocket expenditure. Conversely, patients may seek out care in private hospitals due to geographical convenience or hospital and provider preference. Regardless of reason, care in the private sector has been associated with higher risk of catastrophic expenditures, potentially perpetuating cycles of poverty. ${ }^{37}$

The cost of receiving SAO care in the private sector is detrimental to many patients and is primarily due to the direct cost of the surgical procedure. Greater than $80 \%$ of the population in Chiapas are at risk of catastrophic expenditure when receiving care in the private sector for one of the bellwether procedures. However, about $5 \%$ of patients with public insurance receiving care in public hospitals are also at risk of catastrophic expenditure, which represents more than $80 \%$ of the population. The World Bank had previously estimated that $9 \%$ of the population in Mexico was at risk of catastrophic expenditure due to surgical care. ${ }^{38}$ Although Chiapas is one of the poorest state, a large percentage of the population is covered by the government healthcare scheme which covers in-hospital costs and provides greater financial risk protection than that the average protection in Mexico. The population at risk of catastrophic expenditure in the public sector is lower than that of other Latin American countries, including Colombia (19.4\%) and Brazil (15.4\%). ${ }^{34} 39$ Experiencing catastrophic health expenditure can impact generations as households may be forced to reduce food, housing, clothing or education expenses. ${ }^{40}$ Additionally, households may need to choose between cancelling or postponing SAO care for the patient and selling assets. ${ }^{37}$ Either choice can result in greater financial burden, through the death of a working family member, increased health cost from further advanced disease or intensified poverty from asset loss. ${ }^{37}$

These findings illuminate areas of SAO care that could be improved by targeted interventions in Chiapas and that are applicable to other low-resource settings. First, efforts to improve infrastructure in public hospitals may improve treatment quality and relieve care delays. Ensuring availability of basic infrastructure, airway management equipment, OR equipment and consumables may enable procedures to occur on time and with the appropriate materials. For example, the availability of sutures in all public hospitals could eliminate unnecessary and potentially dangerous delays in SAO care. Governmental investments that could impact the quality of care include direct provision of solar panels and generators for electricity generation, securing running water provision and maintaining functioning autoclaves. ${ }^{41}$ Second, all facilities should enact strategies to increase SAO provider availability and provider matching. To increase provider availability in hospitals in a cost-effective manner, Mexico could increase training of non-physician providers to contribute to $\mathrm{SAO}$ care, such as allowing nurse anaesthetists or training more nurse midwives. ${ }^{42} 43$ Hospitals that have difficulty employing sufficient numbers of providers, especially in rural regions could partner with the Ministry of Health and medical schools to increase student recruitment from local students and among women, who compose only one-quarter of the SAO workforce in Chiapas. Third, efforts to increase data reporting and registry use could enable improved outcome tracking and targeted quality improvement interventions. Data collection could be expanded in the public sector to include sustainable regular collection and analysis of surgical data from the SAT and the six LCoGS indicators to be used for benchmarking, quality improvement and resource allocation. This could enable the Ministry of Health to take efficient action to improve SAO care in public hospitals. Uniform data collection, including prices, in the private sector should be a baseline requirement, and this information should be publicly available to drive competition. Publicly available private data could improve SAO outcomes, quality of care and decrease cost to patients. This comprehensive data could inform a strategic state plan to strengthen SAO plan in a coordinated fashion that includes both private and public sectors.

The adoption of these interventions could improve the quality of SAO care delivered to the patient by enabling timely treatment with the appropriate use of resources. Furthermore, these strategies might decrease costs the patient incurs that result from delayed care, purchasing unavailable equipment outside the hospital, and being forced to seek treatment in the private sector.

There are multiple limitations to this study. First, collecting data with the SAT results in potential biases, including ascertainment, recall, observer and interviewer bias. Among private hospitals, there may be incentive for the respondent to over-report equipment availability and under-report mortality, for example. Conversely, respondents from public hospitals may under-report availability of equipment and workforce. A second limitation is the retrospective collection of data from surgical and anaesthesia logbooks in public hospitals. However, logbooks have been found to be complete and accurate. ${ }^{34} 44$ Third, we were unable to collect primary data from all public and private hospitals in Chiapas due to safety, the COVID-19 pandemic and lack of willingness to participate by some hospitals. Specifically, 3 public hospitals were not sampled due to COVID-19 and 37 private hospitals did not choose to participate. While hospitals were sampled from all health districts with bellwether capable Ministry of Health hospitals in the state, it is likely that hospitals not willing to participate in the study have lower surgical capacity and there may be variation between hospitals within the same districts that we were unable to capture. Despite these limitations this is the first study to elucidate overall surgical capacity in a Mexican state.

\section{CONCLUSION}

This study analysed the surgical capacity in Chiapas, Mexico, in the domains of access, infrastructure, service delivery, surgical volume, quality, workforce and financial 
risk protection. Dramatic differences exist in the essential surgical capacity between public and private hospitals, especially with regards to infrastructure, equipment and workforce. Capacity limitations are greater in public hospitals compared with private hospitals. However, the cost of care in the private sector is significantly higher than the public sector and may result in catastrophic expenditures. Robust and sustainable data collection and monitoring and evaluation frameworks could inform targeted interventions formulated within a state-wide SAO plan to improve the infrastructure, workforce, service delivery, financing, information technology and governance are necessary to provide safe, timely, and accessible SAO care to patients in Chiapas.

\section{Author affiliations}

${ }^{1}$ Program in Global Surgery and Social Change, Harvard Medical School, Boston,

Massachusetts, USA

${ }^{2}$ Department of Obstetrics and Gynecology, University of Alberta, Edmonton, Alberta, Canada

${ }^{3}$ Institute for Advanced Study of the Americas, University of Miami, Coral Gables,

Florida, USA

${ }^{4}$ Compañeros En Salud, Jaltenango, Mexico

${ }^{5}$ Hospital Basico Comunitario Angel Albino Corzo, Jaltenango, Mexico

${ }^{6}$ Center for Surgery and Public Health, Brigham and Women's Hospital, Boston,

Massachusetts, USA

${ }^{7}$ Plastic and Oral Surgery, Boston Children's Hospital, Boston, Massachusetts, USA

Correction notice This article has been corrected since it was published. Middle initial has been added for Dr. John G Meara.

Contributors LR: study design and planning, data analysis, drafted manuscript. EM: collected primary data, data analysis, drafted manuscript. ZF: collected primary data, data analysis, manuscript revision. FC: collected primary data, manuscript revision. SM: study planning, data organisation. WW: study planning, manuscript revision. JM: study planning, manuscript revision. RR: study planning, manuscript revision. TU-L: study design and planning, manuscript revision. VM: study design and planning, data organisation, manuscript revision.

Funding We acknowledge the personal donations from Ronda Stryker and William Johnston Global Surgery Fellowship Fund for their funding distributed for support of authors. This is a personal donation and no award or grant number is available.

Map disclaimer The depiction of boundaries on the map(s) in this article does not imply the expression of any opinion whatsoever on the part of BMJ (or any member of its group) concerning the legal status of any country, territory, jurisdiction or area or of its authorities. The map(s) are provided without any warranty of any kind, either express or implied.

Competing interests None declared.

Patient consent for publication Not required.

Ethics approval Institutional Review Board approval was obtained from the Chiapas Ministry of Health Bioethics Committee (approval number 5003/8777). Informed consent from participants was obtained and documented.

Provenance and peer review Not commissioned; externally peer reviewed.

Data availability statement No data are available. All data relevant to the study are included in the article or uploaded as supplemental information.

Supplemental material This content has been supplied by the author(s). It has not been vetted by BMJ Publishing Group Limited (BMJ) and may not have been peer-reviewed. Any opinions or recommendations discussed are solely those of the author(s) and are not endorsed by BMJ. BMJ disclaims all liability and responsibility arising from any reliance placed on the content. Where the content includes any translated material, BMJ does not warrant the accuracy and reliability of the translations (including but not limited to local regulations, clinical guidelines, terminology, drug names and drug dosages), and is not responsible for any error and/or omissions arising from translation and adaptation or otherwise.
Open access This is an open access article distributed in accordance with the Creative Commons Attribution Non Commercial (CC BY-NC 4.0) license, which permits others to distribute, remix, adapt, build upon this work non-commercially, and license their derivative works on different terms, provided the original work is properly cited, appropriate credit is given, any changes made indicated, and the use is non-commercial. See: http://creativecommons.org/licenses/by-nc/4.0/.

\section{ORCID iDs}

Lina Roa http://orcid.org/0000-0001-6552-4452

Ellie Moeller http://orcid.org/0000-0002-3593-1679

\section{REFERENCES}

1 Alkire BC, Raykar NP, Shrime MG, et al. Global access to surgical care: a modelling study. Lancet Glob Health 2015;3:e316-23.

2 Meara JG, Hagander L, Leather AJM. Surgery and global health: a Lancet Commission. The Lancet 2014;383:12-13.

3 Albutt K, Punchak M, Kayima P, et al. Access to safe, timely, and affordable surgical care in Uganda: a stratified randomized evaluation of nationwide public sector surgical capacity and core surgical indicators. World J Surg 2018;42:2303-13.

4 Crandall M, Sharp D, Unger E, et al. Trauma Deserts: distance from a trauma center, transport times, and mortality from gunshot wounds in Chicago. Am J Public Health 2013;103:1103-9.

5 Ivers LC, Garfein ES, Augustin J, et al. Increasing access to surgical services for the poor in rural Haiti: surgery as a public good for public health. World J Surg 2008;32:537-42.

6 Vissoci JRN, Ong CT, Andrade Lde, de AL, et al. Disparities in surgical care for children across Brazil: use of geospatial analysis. PLoS One 2019;14:e0220959.

7 Walton M, Levy S, eds. No growth without equity?: Inequality, interests, and competition in Mexico. Washington, DC: The World Bank, 2009.

8 World Bank Country and Lending Groups. World bank data help desk, 2020. Available: https://datahelpdesk.worldbank.org/ knowledgebase/articles/906519-world-bank-country-and-lendinggroups

9 OECD. Measuring well-being in Mexican states. Paris: OECD, 2015.

10 MapChart. Snapshot, 2020. Available: https://mapchart.net/mexico. html

11 Salinas JJ, Al Snih S, Markides K, et al. The rural-urban divide: health services utilization among older Mexicans in Mexico. The Journal of Rural Health 2010;26:333-41.

12 Tinoco-Ojanguren R, Glantz NM, Martinez-Hernandez I, et al. Risk screening, emergency care, and lay concepts of complications during pregnancy in Chiapas, Mexico. Soc Sci Med 2008;66:1057-69.

13 Ornelas PV. Rural poverty in Mexico: prevalence and challenges. Nat/ Counc Eval Soc Dev Policy 2019.

14 Freyermuth MG, Muños JA, Ochoa MDP. From therapeutic to elective cesarean deliveries: factors associated with the increase in cesarean deliveries in Chiapas. Int J Equity Health 2017;16:88.

15 León-Cortés JL, Leal Fernández G, Sánchez-Pérez HJ. Health reform in Mexico: governance and potential outcomes. Int $J$ Equity Health 2019;18:30.

16 Cubos dinámicos, 2020. Available: http://www.dgis.salud.gob.mx/ contenidos/basesdedatos/BD_Cubos_gobmx.html

17 Ruelas E. Health care quality improvement in Mexico: challenges, opportunities, and progress. Baylor University Medical Center Proceedings 2002;15:319-22.

18 Nigenda G, Wirtz VJ, González-Robledo LM, et al. Evaluating the Implementation of Mexico's Health Reform: The Case of Seguro Popular. Health Systems \& Reform 2015;1:217-28.

19 ISSTECH. ISSTECH - Instituto de Seguridad Social de los Trabajadores del Estado de Chiapas, 2020. Available: https://www. isstech.gob.mx/portal/index.php

20 Strouse C, Perez-Cuevas R, Lahiff M, et al. Mexico's seguro popular appears to have helped reduce the risk of preterm delivery among women with low education. Health Aff 2016;35:80-7.

21 Instituto de Salud para el Bienestar| Gobierno. gob.mx, 2020. Available: https://www.gob.mx/insabi

22 Instituto Nacional de Estadística y Geografía. Panorama Sociodemográfico de Chiapas 2015.

23 Consejo Nacional de Evaluación de la Política de Desarrollo Social. Informe de pobreza Y evaluación 2020. Chiapas.

24 STROBE. STROBE_checklist_v4_cross-sectional.pdf, 2020. Available: https://www.strobe-statement.org/fileadmin/Strobe/ uploads/checklists/STROBE_checklist_v4_cross-sectional.pdf 
25 O'Neill KM, Greenberg SLM, Cherian M, et al. Bellwether procedures for monitoring and planning essential surgical care in low- and middle-income countries: caesarean delivery, laparotomy, and treatment of open fractures. World J Surg 2016;40:2611-9.

26 Truche P, Roa L, Citron I. Bellwether procedures for monitoring Subnational variation of all-cause perioperative mortality in Brazil. World J Surg. Published online 2020.

27 WHO. | who EESC global database. who. accessed may 20, 2020. Available: http://www.who.int/surgery/eesc_database/en/

28 Ppp conversion factor, private consumption (LCU per international \$) | data. accessed April 21, 2020. Available: https://data.worldbank. org/indicator/pa.nus.prvt.pp

29 Contini S, Taqdeer A, Cherian M, et al. Emergency and essential surgical services in Afghanistan: still a missing challenge. World $J$ Surg 2010;34:473-9.

30 Unger-Saldaña K, Ventosa-Santaulària D, Miranda A, et al. Barriers and explanatory mechanisms of delays in the patient and diagnosis intervals of care for breast cancer in Mexico. Oncologist 2018;23:440-53.

31 Roa L, Citron I, Ramos JA, et al. Cross-Sectional study of surgical quality with a novel evidence-based tool for low-resource settings. BMJ Open Qual 2020;9:e000880.

32 Citron I, Saluja S, Amundson J, et al. Surgical quality indicators in low-resource settings: a new evidence-based tool. Surgery 2018;164:946-52.

33 Orlas CP, Herrera-Escobar JP, Zogg CK, et al. Chest trauma outcomes: public versus private level I trauma centers. World J Surg 2020;44:1824-34.

34 Hanna JS, Herrera-Almario GE, Pinilla-Roncancio M, et al. Use of the six core surgical indicators from the Lancet Commission on global surgery in Colombia: a situational analysis. The Lancet Global Health 2020;8:e699-710.
35 Pérez HJ, Cedeño MA. Maternal mortality in Chiapas: an unfinished story. Soc Med 2015;9:48-50.

36 Knight HE, Self A, Kennedy SH. Why are women dying when they reach hospital on time? A systematic review of the 'Third Delay'. PLoS One 2013;8:e63846.

37 Lagana MMH. Evaluating the impact of catastrophic health payments on school interruption: the case of Mexico 2014;55.

38 Data. Risk of catastrophic expenditure for surgical care (\% of people at risk), 2020. Available: https://data.worldbank.org/indicator/SH. SGR.CRSK.ZS

39 Alonso N, Massenburg BB, Galli R, et al. Surgery in Brazilian health care: funding and physician distribution. Rev Col Bras Cir 2017;44:202-7.

40 Agrawal R, Negi R, Kaushal SK, et al. Out of pocket expenditure and its associated factors in neonates admitted to neonatal intensive care unit of tertiary care government hospital of Agra district, Uttar Pradesh. Indian J Public Health 2020;64:60-5.

41 Linden AF, Sekidde FS, Galukande M, et al. Challenges of surgery in developing countries: a survey of surgical and anesthesia capacity in uganda's public hospitals. World J Surg 2012;36:1056-65.

42 Reid ML, Morris JB, Care P. Perinatal care and cost effectiveness: changes in health expenditures and birth outcome following the establishment of a nurse-midwife program. Med Care 1979;17:491-500.

43 Stanik-Hutt J, Newhouse RP, White KM, et al. The quality and effectiveness of care provided by nurse practitioners. The Journal for Nurse Practitioners 2013;9:492-500.

44 Anderson GA, Ilcisin L, Abesiga L, et al. Surgical volume and postoperative mortality rate at a referral hospital in Western Uganda: measuring the Lancet Commission on global surgery indicators in low-resource settings. Surgery 2017;161:1710-9. 